\section{Terrestrial nitrogen cycling in Earth system models revisited}

\section{'Terrestrial nitrogen cycling in Earth system models' Workshop, Dartington Hall, Devon, UK, February 2016}

Understanding the degree to which nitrogen $(\mathrm{N})$ availability limits land carbon (C) uptake under global environmental change represents an unresolved challenge. First-generation 'C-only' vegetation models, lacking explicit representations of $\mathrm{N}$ cycling, projected a substantial and increasing land $\mathrm{C}$ sink under rising atmospheric $\mathrm{CO}_{2}$ concentrations. This prediction was questioned for not taking into account the potentially limiting effect of $\mathrm{N}$ availability, which is necessary for plant growth (Hungate et al., 2003). More recent global models include coupled $\mathrm{C}$ and $\mathrm{N}$ cycles in land ecosystems (C-N models) and are widely assumed to be more realistic. However, inclusion of more processes has not consistently improved their performance in capturing observed responses of the global C cycle (e.g. Wenzel et al., 2014). With the advent of a new generation of global models, including coupled $\mathrm{C}, \mathrm{N}$, and phosphorus (P) cycling, model complexity is sure to increase; but model reliability may not, unless greater attention is paid to the correspondence of model process representations and empirical evidence. It was in this context that the 'Nitrogen Cycle Workshop' at Dartington Hall, Devon, UK was held on 1-5 February 2016. Organized by I. Colin Prentice and Benjamin D. Stocker (Imperial College London, UK), the workshop was funded by the European Research Council, project 'Earth system Model Bias Reduction and assessing Abrupt Climate change' (EMBRACE). We gathered empirical ecologists and ecosystem modellers to identify key uncertainties in terrestrial $\mathrm{C}-\mathrm{N}$ cycling, and to discuss processes that are missing or poorly represented in current models.

¿.. future experiments should be specifically designed to identify constraints set by resource availability and tradeoffs caused by intrinsic physiological limitations.'

\section{Openness of the nitrogen cycle}

We started by addressing how $\mathrm{N}$ cycling varies at large spatial scales. Nitrogen cycle openness can be quantified as the ratio between 'new
$\mathrm{N}$ ' inputs and total internal $\mathrm{N}$ cycling (see Fig. 1). While consensus appears to suggest an increase in $\mathrm{N}$ cycle openness from boreal to tropical and in particular Savannah ecosystems (Cleveland et al., 2013), models and empirical estimates diverge on the strength of this gradient (Sönke Zaehle, MPI-BGC, Germany).

These quantifications hinge partly on estimates of biological $\mathrm{N}$ fixation, for which a recent top-down analysis suggests a global rate of $58 \mathrm{Tg} \mathrm{N} \mathrm{yr}^{-1}$ (Vitousek et al., 2013) - much lower than the earlier estimate by Cleveland et al. (1999) of 100 to $290 \mathrm{Tg} \mathrm{N} \mathrm{yr}^{-1}$. New measurements in tropical forests (Sullivan et al., 2014) are consistent with this downward correction. However, remarkably large uncertainties remain. Sasha Reed (US Geological Survey, USA) emphasized the surprising variety of $\mathrm{N}$-fixing organisms that have only recently been discovered in different habitats (Reed et al., 2011) and the high degree of variability in fixation rates with stand age in tropical forests (Batterman et al., 2013). Several participants pointed to remaining challenges in measuring $\mathrm{N}$ fixation rates in the field and, in particular, the likely underestimation of free-living $\mathrm{N}$ fixation in current estimates. For example Elbert et al. (2012) estimated $\mathrm{N}$ fixation in cryptogamic covers alone at $49 \mathrm{Tg} \mathrm{N} \mathrm{yr}^{-1}$. Moreover, Taraka Davies-Barnard (University of Exeter, UK), Andy Wiltshire (MetOffice, UK), and Karin Rebel (Utrecht University, the Netherlands) noted that from a modelling perspective, it is essential not only to quantify the magnitude of the $\mathrm{N}$ fixation flux, but also to understand its controls and its energetic (C) cost. Indeed, mechanisms have been identified that imply a (limited) plant control over $\mathrm{N}$ fixation rates (Menge \& Hedin, 2009), including labile C export by plants to free-living N-fixing heterotrophs (Reed et al., 2011). Finally, John Raven (Dundee University, UK) discussed key insights into the physiological processes of $\mathrm{N}$ fixation.

Sarah Cornell (Stockholm Resilience Centre, Sweden) pointed out that the other major component of new $\mathrm{N}$ inputs, atmospheric deposition, may also be underestimated. Deposition of organic N forms has generally been ignored, but can be substantial in remote areas due to their longer atmospheric lifetimes and transport ranges compared to $\mathrm{NO}_{x}$ (Neff et al., 2002). In view of the increasing appreciation of organic $\mathrm{N}$ in plant nutrition, as noted by Torgny Näsholm (Umeå Plant Science Centre, Sweden), a re-assessment of $\mathrm{N}$ cycle openness in boreal systems may be required.

Adrien Finzi (Boston University, MA, USA) presented a global compilation of mineralization rates and compared these with the fraction of total gross primary productivity (GPP) allocated belowground. The derived pattern reveals a high $\mathrm{C}$-cost of $\mathrm{P}$ acquisition but a low apparent- $\mathrm{C}$ cost of $\mathrm{N}$ acquisition in the tropics, consistent with 'open' N cycling. By contrast, Ivan Janssens and Sara Vicca (both University of Antwerp, Belgium) reported low biomass production efficiency (ratio of biomass production to GPP) in tropical forests, and suggested this reflects high C costs of nutrient acquisition. The spatial scale of the studies varies 


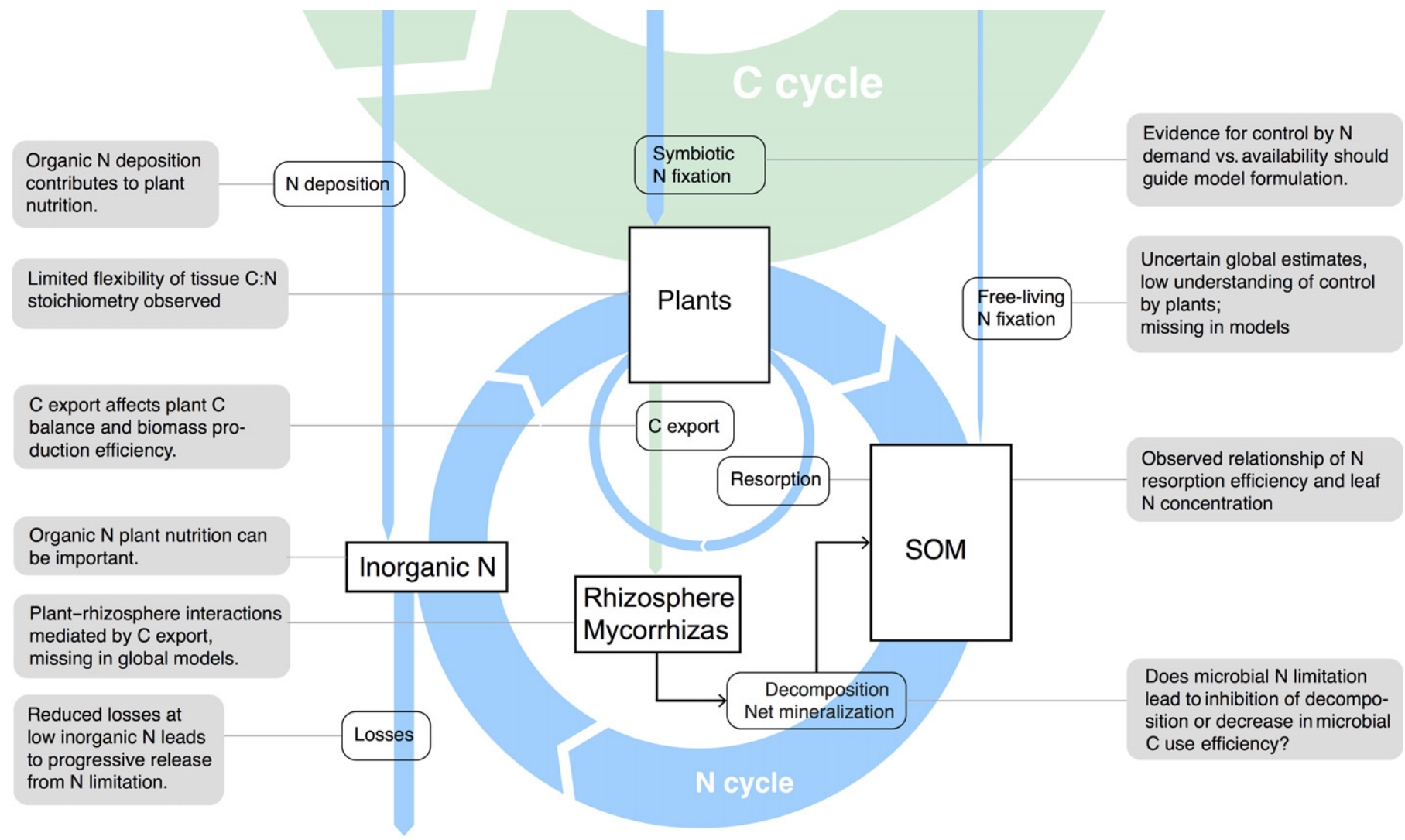

Fig. 1 Summary of findings and research priorities emerging from the workshop 'Terrestrial nitrogen cycling in Earth system models'. The thickness of arrows qualitatively illustrates the relative magnitude of fluxes. Nitrogen $(\mathrm{N})$ cycle openness is illustrated by the relative flux magnitudes of losses or inputs (arrows for $\mathrm{N}$ deposition, symbiotic $\mathrm{N}$ fixation, and free-living $\mathrm{N}$ fixation) vs internal cycling (circles). SOM, soil organic matter.

substantially, and various possibilities exist to explain this discrepancy (higher rates of autotrophic respiration among others). Additional research is necessary to reconcile these two reports. Their studies do, however, point to large scale gradients of $\mathrm{N}$ cycle openness, total belowground allocation, and biomass production efficiency as prime benchmarks for a new generation of $\mathrm{C}-\mathrm{N}$ models.

\section{Nitrogen constraints on plant $\mathrm{CO}_{2}$ responses}

The positive effect of elevated $\mathrm{CO}_{2}$ on leaf-level photosynthesis implies a shift in the balance of supply and demand for $\mathrm{C}$ vs $\mathrm{N}$. We went on to discuss respective effects on plant-soil interactions. Sönke Zaehle reported that current $\mathrm{C}-\mathrm{N}$ models, in contrast to measurements in Free Air $\mathrm{CO}_{2}$ Enrichment (FACE) experiments, achieve a positive response in net primary productivity (NPP) primarily by increasing $\mathrm{C}: \mathrm{N}$ at the tissue level (Zaehle et al., 2014); however, the models fail to reproduce the observed shift towards belowground $\mathrm{C}$ allocation and increased $\mathrm{N}$ uptake. Ivan Janssens reported that leaf $\mathrm{N}$ concentrations across European forests is co-determined by phylogeny and, while spatial differences in stoichiometry within plant species can be large, temporal responses to environmental change appear small (Sardans etal., 2015). It became clear that stoichiometric flexibility in different plant tissues and leaf-level photosynthetic capacity - as well as their response to changes in atmospheric $\mathrm{CO}_{2}$ and soil nutrient availability - warrant special attention from empiricists, as well as in the formulation of models.
While overestimating the role of stoichiometric flexibility, current $\mathrm{C}-\mathrm{N}$ models allow limited scope for shifts in $\mathrm{C}$ allocation when $\mathrm{N}$ availability is low. Recent research has highlighted the importance of mycorrhizas (Phillips et al., 2013) and plantcontrolled rhizosphere priming effects (Cheng et al., 2014; Finzi et al., 2015). Oskar Franklin (IIASA, Laxenburg, Austria) pointed out that mycorrhizal associations may aggravate $\mathrm{N}$ limitation under low $\mathrm{N}$ availability due to their $\mathrm{N}$ immobilization, thereby reducing a positive $\mathrm{CO}_{2}$ fertilization effect (Franklin et al., 2014). But Sara Vicca and César Terrer (Imperial College London, UK) showed contrasting new results from a meta-analysis of experimental data. Under low $\mathrm{N}$, a positive biomass production response under elevated $\mathrm{CO}_{2}$ does appear in plants associated with ectomycorrhizal fungi, but not in plants associated with arbuscular mycorrhizas. A similar mechanism may be at work for N-fixing species. Tuula Larmola (Natural Resources Institute, Helsinki, Finland) reported that in an environment with very low N deposition, Sphagnumassociated $\mathrm{N}$ fixation may far exceed atmospheric deposition and thus enable sustained $\mathrm{C}$ accumulation in peatlands (Larmola $e t a l$., 2014). Sönke Zaehle showed results of a global modelling study indicating that assumptions regarding the controls on $\mathrm{N}$ fixation have major implications for its response to rising $\mathrm{CO}_{2}$. He posed the question 'How do we put the brakes on $\mathrm{N}$ fixation?'. But interestingly, the implications of resolving $\mathrm{N}$ fixation controls over the global land C balance are limited (Meyerholt et al., 2016). This may be linked to the fact that $\mathrm{C}-\mathrm{N}$ models that resolve the 
dynamics of a soil inorganic $\mathrm{N}$ pool, and simulate $\mathrm{N}$ loss as a function of the pool's size, suggest that even in the absence of a strong amplification of $\mathrm{N}$ fixation there is a progressive release from $\mathrm{N}$ limitation on a decadal timescale, due to increased ecosystem $\mathrm{N}$ retention (Walker et al., 2015).

In view of the $\mathrm{C}$ costs for $\mathrm{N}$ fixation and subsidising rhizosphere activity and mycorrhizas, Adrien Finzi asked the question: 'Is $\mathrm{N}$ limitation just C limitation in disguise?'. Successfully modelling plant $\mathrm{C}$ allocation is key to predicting effects of environmental change. Simple models based on optimality principles have been proposed (Franklin et al., 2012) and may guide the development of a next generation of $\mathrm{C}-\mathrm{N}$ models. Along the way, it will be important to make good use of data from manipulation experiments to test models at the level of individual processes. Conversely, future experiments should be specifically designed to identify constraints set by resource availability and trade-offs caused by intrinsic physiological limitations.

\section{The representation of soil nitrogen cycling in models}

The CENTURY paradigm for modelling transformations of $\mathrm{C}$ and $\mathrm{N}$ in soils received a mixed response from participants. It was agreed that this modelling approach has stood the test of time, above all as a means for modelling the effects of land-use changes on the dynamics of soil C. However, Ivan Janssens noted that the observed response to $\mathrm{N}$ deposition is a reduction of heterotrophic respiration relative to NPP (Janssens etal., 2010); opposite to what CENTURY-type models predict. Consistent with reduced respiration with increasing $\mathrm{N}$ availability, Stefano Manzoni (Stockholm University, Sweden) drew attention to evidence that the C-use efficiency of microbes may decrease with increasing organic matter C : N (Manzoni etal., 2012). This supports an increasingly widespread view that more explicitly representing microbial function in soil models will be required to explain these observations and adequately account for plant-soil interactions.

In this respect, and in general, appropriate compromises have to be found in the dilemma between model realism and tractability. This should be guided by key observational phenomena required to be captured by models, data availability for model evaluation, and the principle that everything should be made as simple as possible, but not simpler.

\section{Acknowledgements}

Many thanks go to Dr Natalie Sanders for running this conference. The authors also thank César Terrer for helpful comments on the report. The workshop was funded by the ERC FP7 through project EMBRACE (282672).

Benjamin D. Stocker ${ }^{1 *}$, I. Colin Prentice ${ }^{2}$, Sarah E. Cornell ${ }^{3}$, Taraka Davies-Barnard ${ }^{4}$, Adrien C. Finzi ${ }^{5}$, Oskar Franklin ${ }^{6}$, Ivan Janssens ${ }^{7}$, Tuula Larmola ${ }^{8}$, Stefano Manzoni ${ }^{\text {', }}$ Torgny Näsholm ${ }^{10}$, John A. Raven ${ }^{11}$, Karin T. Rebel ${ }^{12}$, Sasha Reed ${ }^{13}$, Sara Vicca ${ }^{7}$, Andy Wiltshire ${ }^{14}$ and Sönke Zaehle ${ }^{15}$
${ }^{1}$ Department of Life Sciences and Grantham Institute for Climate Change, Imperial College London, Silwood Park, Ascot, SL5 7PY,

$\mathrm{UK}$;

${ }^{2}$ AXA Chair of Biosphere and Climate Impacts, Department of Life Sciences and Grantham Institute for Climate Change, Imperial College London, Silwood Park, Ascot, SL5 7PY, UK;

${ }^{3}$ Stockholm Resilience Centre, Stockholm University, SE-106 91, Stockholm, Sweden;

${ }^{4}$ College of Engineering, Mathematics and Physical Sciences, University of Exeter, Harrison Building, Streatham Campus, EX4 $4 \mathrm{QF}, \mathrm{UK}$

${ }^{5}$ Department of Biology and $\mathrm{PhD}$ Programme in Biogeoscience, Boston University, Boston, MA 02215, USA;

${ }^{6}$ IIASA - International Institute for Applied Systems Analysis, A-2361 Laxenburg, Austria;

${ }^{7}$ Department of Biology, University of Antwerp, 2610 Wilrijk,

Belgium;

${ }^{8}$ Natural Resources Institute Finland (Luke), Jokiniemenkuja 1, 01370 Vantaa, Finland;

${ }^{9}$ Department of Physical Geography, Stockholm University and Bolin Centre for Climate Research, Svante Arrhenius väg 8, Frescati, SE-10691 Stockholm, Sweden;

${ }^{10}$ Department of Forest Ecology and Management, Swedish University of Agricultural Sciences, 90183 Umeå, Sweden; ${ }^{11}$ Plant Sciences, University of Dundee at JHI, Errol Road, Invergowrie, Dundee, DD2 5DA, UK;

${ }^{12}$ Copernicus Institute of Sustainable Development, Environmental Sciences, Heidelberglaan 2, 3584 CS Utrecht, the Netherlands;

${ }^{13}$ US Geological Survey, Southwest Biological Science Centre, Moab, UT 84532, USA;

${ }^{14}$ Met Office, FitzRoy Road, Exeter, EX1 3PB, UK;

${ }^{15}$ Biogeochemical Integration Department, Max Planck Institute for Biogeochemistry, Hans-Knoell-Str. 10, D-07745 Jena,

Germany

(*Author for correspondence: tel +41 7967040 27; email b.stocker@imperial.ac.uk)

\section{References}

Batterman SA, Hedin LO, van Breugel M, Ransijn J, Craven DJ, Hall JS. 2013. Key role of symbiotic dinitrogen fixation in tropical forest secondary succession. Nature 502: 224-227.

Cheng W, Parton WJ, Gonzalez-Meler MA, Phillips R, Asao S, McNickle GG, Brzostek E, Jastrow JD. 2014. Synthesis and modeling perspectives of rhizosphere priming. New Phytologist 201: 31-44.

Cleveland C, Townsend A, Schimel D, Fisher H, Howarth R, Hedin L, Perakis S, Latty E, Von Fischer J, Elseroad A et al. 1999. Global patterns of terrestrial biological nitrogen $\left(\mathrm{N}_{2}\right)$ fixation in natural ecosystems. Global Biogeochemical Cycles 13: 623-645.

Cleveland CC, Houlton BZ, Smith WK, Marklein AR, Reed SC, Parton W, Del Grosso SJ, Running SW. 2013. Patterns of new versus recycled primary production in the terrestrial biosphere. Proceedings of the National Academy of Sciences, USA 110: 12733-12737.

Elbert W, Weber B, Burrows S, Steinkamp J, Buedel B, Andreae MO, Poeschl U. 2012. Contribution of cryptogamic covers to the global cycles of carbon and nitrogen. Nature Geoscience 5: 459-462. 
Finzi AC, Abramoff RZ, Spiller KS, Brzostek ER, Darby BA, Kramer MA, Phillips RP. 2015. Rhizosphere processes are quantitatively important components of terrestrial carbon and nutrient cycles. Global Change Biology 21: 2082-2094.

Franklin O, Johansson J, Dewar RC, Dieckmann U, McMurtrie RE, Brännström Å, Dybzinski R. 2012. Modeling carbon allocation in trees: a search for principles. Tree Physiology 32: 648-666.

Franklin O, Näsholm T, Högberg P, Högberg MN. 2014. Forests trapped in nitrogen limitation - an ecological market perspective on ectomycorrhizal symbiosis. New Phytologist 203: 657-666.

Hungate B, Dukes J, Shaw M, Luo Y, Field C. 2003. Nitrogen and climate change. Science 302: 1512-1513.

Janssens IA, Dieleman W, Luyssaert S, Subke J-A, Reichstein M, Ceulemans R, Ciais P, Dolman AJ, Grace J, Matteucci G et al. 2010. Reduction of forest soil respiration in response to nitrogen deposition. Nature Geoscience 3: 315-322.

Larmola T, Leppänen SM, Tuittila E-S, Aarva M, Merilä P, Fritze H, Tiirola M. 2014. Methanotrophy induces nitrogen fixation during peatland development. Proceedings of the National Academy of Sciences, USA 111: 734-739.

Manzoni S, Taylor P, Richter A, Porporato A, Ågren GI. 2012. Environmental and stoichiometric controls on microbial carbon-use efficiency in soils. New Phytologist 196: 79-91.

Menge DNL, Hedin LO. 2009. Nitrogen fixation in different biogeochemical niches along a 120 000-year chronosequence in New Zealand. Ecology 90: 2190-2201.

Meyerholt J, Zaehle S, Smith MJ. 2016. Variability of projected terrestrial biosphere responses to elevated levels of atmospheric $\mathrm{CO}_{2}$ due to uncertainty in biological nitrogen fixation. Biogeosciences 13: 1491-1518.

Neff JC, Holland EA, Dentener FJ, McDowell WH, Russell KM. 2002. The origin, composition and rates of organic nitrogen deposition: a missing piece of the nitrogen cycle? Biogeochemistry 57-58: 99-136.

Phillips RP, Brzostek E, Midgley MG. 2013. The mycorrhizal-associated nutrient economy: a new framework for predicting carbon-nutrient couplings in temperate forests. New Phytologist 199: 41-51.
Reed SC, Cleveland CC, Townsend AR. 2011. Functional ecology of free-living nitrogen fixation: a contemporary perspective. Annual Review of Ecology, Evolution, and Systematics 42: 489-512.

Sardans J, Janssens IA, Alonso R, Veresoglou SD, Rillig MC, Sanders TGM, Carnicer J, Filella I, Farré-Armengol G, Peñuelas J. 2015. Foliar elemental composition of European forest tree species associated with evolutionary traits and present environmental and competitive conditions. Global Ecology and Biogeography 24: 240-255.

Sullivan BW, Smith WK, Townsend AR, Nasto MK, Reed SC, Chazdon RL, Cleveland CC. 2014. Spatially robust estimates of biological nitrogen (N) fixation imply substantial human alteration of the tropical $\mathrm{N}$ cycle. Proceedings of the National Academy of Sciences, USA 111: 8101-8106.

Vitousek PM, Menge DNL, Reed SC, Cleveland CC. 2013. Biological nitrogen fixation: rates, patterns and ecological controls in terrestrial ecosystems. Philosophical Transactions of the Royal Society of London B: Biological Sciences 368: 20130119

Walker AP, Zaehle S, Medlyn BE, De Kauwe MG, Asao S, Hickler T, Parton W, Ricciuto DM, Wang Y-P, Wårlind D et al. 2015. Predicting long-term carbon sequestration in response to $\mathrm{CO}_{2}$ enrichment: how and why do current ecosystem models differ? Global Biogeochemical Cycles 29: 476-495.

Wenzel S, Cox PM, Eyring V, Friedlingstein P. 2014. Emergent constraints on climate-carbon cycle feedbacks in the CMIP5 Earth system models. Journal of Geophysical Research: Biogeosciences 119: 794-807.

Zaehle S, Medlyn BE, De Kauwe MG, Walker AP, Dietze MC, Hickler T, Luo Y Wang Y-P, El-Masri B, Thornton P et al. 2014. Evaluation of 11 terrestrial carbon-nitrogen cycle models against observations from two temperate Free-Air $\mathrm{CO}_{2}$ Enrichment studies. New Phytologist 202: 803-822.

Key words: carbon allocation, carbon cycle, Earth system model, exudates, mycorrhiza, nitrogen cycle, nitrogen fixation, plant-soil interactions.

\section{About New Phytologist}

- New Phytologist is an electronic (online-only) journal owned by the New Phytologist Trust, a not-for-profit organization dedicated to the promotion of plant science, facilitating projects from symposia to free access for our Tansley reviews.

- Regular papers, Letters, Research reviews, Rapid reports and both Modelling/Theory and Methods papers are encouraged. We are committed to rapid processing, from online submission through to publication 'as ready' via Early View - our average time to decision is $<27$ days. There are no page or colour charges and a PDF version will be provided for each article.

- The journal is available online at Wiley Online Library. Visit www.newphytologist.com to search the articles and register for table of contents email alerts.

- If you have any questions, do get in touch with Central Office (np-centraloffice@lancaster.ac.uk) or, if it is more convenient, our USA Office (np-usaoffice@lancaster.ac.uk)

- For submission instructions, subscription and all the latest information visit www.newphytologist.com 